\title{
Sociodemographic Aspects of Antibiotic Consumption Practices in Residents of Wah
}

Hina Shan ${ }^{1}$, Ayesha Javaid $^{2}$, Anam Zeb $^{3}$, Saadia Maqbool ${ }^{4}$

\section{ABSTRACT}

Objective: To assess the frequency of antibiotic use with or without prescription and the source of purchasing antibiotics in relation to social determinants among residents of Wah, Pakistan.

Study Design: Cross sectional.

Place and Duration of Study: The study was carried out in the community of Wah Cantt from January 2017 to December 2017.

Materials and Methods: A two stage cluster random sampling technique was used. 400 participants aged 16 years and older, completed the validated questionnaire. Chi-square test of significance was applied to determine the relationship between categorical variables and a $p$-value $<0.05$ was considered significant.

Results: Use of antibiotics in the preceding month was reported by 110 (27.6\%) participants, 101 (25.3\%) reported having taken antibiotics in the last six months. Use of antibiotics was more in males in all categories as compared to females (chi-square $=15.778, p=0.008$ ). The analysis showed that individuals between 55-64 years of age had taken antibiotics in last month (69.2\%). Government employees showed the highest percentage $(36.5 \%)$ of respondents who consumed antibiotics in last one month as compared to any other profession. Overall, most respondents $277(82.7 \%)$ reported that they got their antibiotics on a prescription from doctors.

Conclusion: Effective education along with close vigilance for the judicious use of antibiotic prescribing should be aimed at both the prescribers and the public. Better knowledge is associated with correct behavior of antibiotic/antimicrobial use.

Key Words: Antibiotics, Antibiotic Consumption, Antibiotic Prescription, Antibiotic Resistance, Antimicrobial Resistance.

How to cite this: Shan H, Javaid A, Zeb A, Maqbool S. Socio Demographic Aspects of Antibiotic Consumption Practices in Residents of Wah. Life and Science. 2020; 1(1): 16-22. doi: http://doi.org/10.37185/LnS.1.1.28

\section{Introduction}

Antibiotics are the most commonly prescribed antimicrobial medicines for prevention and treatment of bacterial infections. The increase in antimicrobial resistance is multifactorial, but irrational use along with higher consumption of antibiotic are considered chief determinants in

${ }^{1}$ Department of Community Medicine HBS Medical College, Islamabad

${ }^{2}$ Department of Community Medicine Al-Nafees Medical Collage, Islamabad

${ }^{3}$ Department of Pathology/Community Medicine ${ }^{4}$

Army Medical College

National University of Medical Sciences

Rawalpindi

Correspondence:

Dr. Hina Shan

Assistant Professor, Community Medicine

HBS Medical College, Islamabad

E-mail:drhinashan@gmail.com

Funding Source: NIL; Conflict of Interest: NIL

Received: Oct 08, 2018; Revised: Oct 16, 2019

Accepted: Dec 02, 2019

16 development of antibiotic resistance worldwide, including Pakistan. ${ }^{1-4}$ The global menace of antibiotic resistance results in lengthier hospital stays, higher medical costs and increased mortality. ${ }^{1,3,5,6}$ Due to accelerated phenomenon of antibiotic resistance, world is heading to a post-antibiotic era, in which infections and minor injuries will once again kill. ${ }^{1,4,-9}$ The conventional antibiotic pipeline remains thin with only few new antibiotics in development to treat the most dangerous infections making antibiotic resistance a big public health concern with threats to food security and development. ${ }^{9-11}$

Worldwide, more than two million people become infected with bacteria that are resistant to antibiotics and 700,000 deaths per year occur due to infections that are resistant to antibiotics. ${ }^{6}$ Pakistan is one of the many low and middle income countries (LMICs) where diseases like pneumonia, acute respiratory tract infections and gonorrhea, have become difficult to treat. ${ }^{12}$ Extensively drug- resistant 
tuberculosis (XDR-TB) has become resistant to at least four of the principal anti-tuberculosis drugs. ${ }^{13}$ Drug-resistant tuberculosis is killing 250,000 people annually in over hundred countries. ${ }^{14,15}$ Multidrug resistance is a grave concern in Pakistan as more than $90 \%$ of participants were positive when tested for multidrug-resistant bacteria in a study conducted by the World Health Organization (WHO). ${ }^{16}$ High connectivity between countries have resulted in the spread of resistant bacteria. Much of the overuse of antimicrobials, chiefly antibiotics, is reported in LMICs, especially in BRICS (Brazil, Russia, India, China, \& South Africa) nations. ${ }^{17,18}$ Pakistan's close proximity with China and India makes it more vulnerable to this leading global health issue. Pakistan and other LMICs will be facing a massive challenge of the double burden of disease due to antibiotic resistance. ${ }^{17,19,20}$ Achievements of modern medicine are threatened because of the fact that these medicines will not be able to provide successful prevention and treatment to various communicable and non-communicable diseases (NCDs). ${ }^{1,8,17,20}$

A recently published study indicates that in many countries (Australia, France, Italy, Hungry, Malta, New Zealand, Norway, Netherlands, Poland) community dispensing covers approximately $85 \%$ $95 \%$ of the total antibacterial supply. ${ }^{21}$ Evidence from previous studies suggests that in health care settings, antibacterial medications are usually used for the treatment of diseases of viral origin that cannot respond to antibiotics. ${ }^{22}$ Over prescription from clinicians, just to be 'on the safe side' and sometimes in response to patients' demand result in the development of the perception in the general public that antibiotics are necessary and safe for symptoms of nonbacterial diseases. ${ }^{23}$ Furthermore, injudicious use of antibiotics in developing countries is the result of patients' past experiences, high cost of health care, non-regulatory sale, insufficient knowledge, demanding unneeded antibiotics, misperception and also self-medication. ${ }^{4,16,17,24-26}$ Sources of selfmedication may comprise taking leftover drugs from treatment courses prescribed earlier or using antibiotics given to friends family for similar symptoms. ${ }^{27}$ Antibiotic use without medical direction or advice is inappropriate because inadequate dosages, incorrect dosage interval and not completing the duration of therapy increases the risk of the spread of antibiotic resistance. ${ }^{28}$

It is imperative to evaluate the relative magnitude of community antibacterial consumption in a country like Pakistan because of increased antibacterial consumption, easy access, availability, along with irrational prescription of antibiotics due to lack of laboratory facilities, non-adherence to clinical practice guidelines, incompetency of health care professionals, and cultural beliefs. ${ }^{16,27,29,30}$ In addition, little information exists on factors that put persons at risk for self-medication. The WHO has stressed on the significant role of the public as well as the prescribers in the effective management of antibiotic resistance. ${ }^{31}$

This study explored the factors that are linked with general publics' practice of antibiotic consumption. The aim was to estimate the extent, prevalence, attitude, and trends in the use of non-prescription antibiotics and sources of acquiring/purchasing antibiotics in Wah, Pakistan.

\section{Materials and Methods}

This cross-sectional study was conducted using two stage cluster random sampling technique in four sectors (randomly chosen out of the total 27 sectors) of Wah Cantt from January to December 2017. WHO sample size calculator was used, with the following assumptions of antibiotics usage of $57 \%$, confidence level of $95 \%$ and $5 \%$, absolute precision required. The sampling frame was obtained from station headquarters, Wah Cantt after taking permission from local authorities. Systematic data collection was done from every fifth house and the first person contacted who fulfilled the eligibility criteria. Inclusion criteria was of participants who were 16 years old or older, were able to read Urdu or English language, and were mentally and physically capable of answering. A validated, closed-ended WHO questionnaire, previously used by WHO in a multicountry survey was administered both in English and Urdu languages (Urdu translation was evaluated using the standard forward and backward method). ${ }^{32}$ Institutional ethical approval was taken from Ethical Review Committee of Army Medical College, National University of Medical Sciences, Rawalpindi. A total of 400 participants completed the questionnaire with written informed consent. Data was entered and analyzed using IBM SPSS (version 
22.0). Mean and standard deviation were calculated for continuous variables. Categorical variables were presented by frequency and percentage. Crosstabulation was done to determine the association between level of knowledge around the appropriate use of antibiotics, when to discontinue antibiotics course and the conditions/illnesses antibiotics treat. To determine the relationship between other categorical variables, chi-square test of significance was applied, and a $p$-value $<0.05$ was significant.

\section{Results}

A sample of adults aged 16 to 72 years were included in the survey with a total of 400 respondents. Of the total, 239 (59.8\%) were males. Mean age was $37.52 \pm$ 10.09 years (Table 1 ).

Table 1: Summary of Sociodemographic Characteristics of Study Participants ( $\mathrm{N}=400$ )

\begin{tabular}{|c|c|c|}
\hline Variable & $\begin{array}{l}\text { Number } \\
\text { (N) }\end{array}$ & $\begin{array}{l}\text { Percentage } \\
(\%)\end{array}$ \\
\hline \multicolumn{3}{|l|}{ Gender } \\
\hline Male & 239 & 59.8 \\
\hline Female & 161 & 40.2 \\
\hline \multicolumn{3}{|l|}{ Age groups (years) } \\
\hline $16-24$ & 29 & 7.2 \\
\hline $25-34$ & 145 & 36.3 \\
\hline $35-44$ & 127 & 31.8 \\
\hline $45-54$ & 79 & 19.8 \\
\hline $55-64$ & 13 & 3.3 \\
\hline 65 plus & 7 & 1.8 \\
\hline \multicolumn{3}{|l|}{ House hold composition } \\
\hline Single adult only & 70 & 17.5 \\
\hline $\begin{array}{l}\text { Single adult and at least one child } \\
\text { under } 16\end{array}$ & 11 & 2.8 \\
\hline Married adults only & 71 & 17.8 \\
\hline $\begin{array}{l}\text { Married and at least one child under } \\
16\end{array}$ & 132 & 33.0 \\
\hline Multiple adults aged 16 and above & 55 & 13.8 \\
\hline $\begin{array}{l}\text { Multiple adults and at least one child } \\
\text { under } 16\end{array}$ & 61 & 15.3 \\
\hline \multicolumn{3}{|l|}{ Education } \\
\hline Primary or middle & 73 & 18.3 \\
\hline Secondary or higher secondary & 140 & 35.0 \\
\hline Bachelor's or equivalent & 126 & 31.5 \\
\hline Master's or equivalent & 61 & 15.3 \\
\hline \multicolumn{3}{|l|}{ Occupation } \\
\hline Government employees & 140 & 35.0 \\
\hline Businessmen/private employees & 109 & 27.3 \\
\hline Doctors & 23 & 5.8 \\
\hline $\begin{array}{l}\text { Other professionals (teachers, } \\
\text { engineers etc.) }\end{array}$ & 69 & 17.3 \\
\hline Students & 32 & 8.0 \\
\hline Jobless/retired/housewives & 27 & 6.8 \\
\hline
\end{tabular}

\begin{tabular}{lcc}
\hline Monthly Household Income in & & \\
Pakistani Rupees (PKR) & & \\
First $\backslash$ poorest Quintile $(<20000$ PKR) & 88 & 22.0 \\
Second Quintile $(\geq 20000<30000$ & 178 & 44.5 \\
PKR) & & \\
Third Quintile $\geq 30000<40000$ PKR) & 48 & 12.0 \\
Fourth Quintile $\quad \geq 40000<65000$ & 40 & 10.0 \\
PKR) & & \\
Fifth $\backslash$ richest Quintile $(\geq 65000$ PKR) & 46 & 11.5 \\
\hline
\end{tabular}

Antibiotic consumption practices were assessed by asking when the last time antibiotics were used (in the last one month, six months back, last year or a year before) by the respondents. Also, how the antibiotics were obtained (prescription or nonprescription medication), and the source of purchasing or acquiring antibiotics (pharmacy, doctors, friends or relatives, online purchase). Use of antibiotics in the last month was reported by 110 (27.6\%) of the participants, 101 (25.3\%) reported having taken antibiotics in the last six months. Fifty (12.5\%) of the respondents reported of having used antibiotics in the last year. A total of 65 participants never used antibiotics or did not remember using antibiotics (9.20\%, 7.10\% respectively). The details are shown in figure 1.

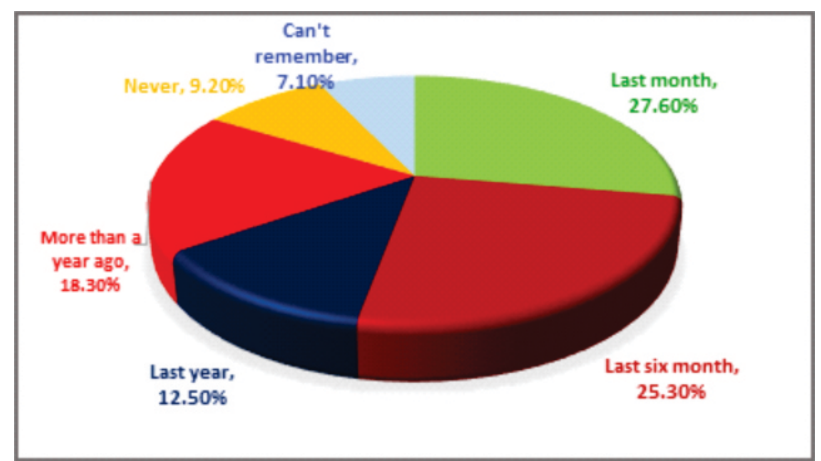

Fig 1: Responses showing the Last Time of Antibiotics Consumption

Some significant differences were identified in antibiotic consumption among various sociodemographic groups/strata. In comparison with gender, 68 (28.4\%) males and 42 (26\%) females consumed antibiotics in the last one month out of the total of 110 . Overall previous use of antibiotics was more in males in all the categories as compared to females and this difference in consumption of antibiotics based on gender was found to be statistically significant (chi-square $=15.778, p=$ 0.008).

The analysis showed that in the in last month 
category, the 55-64 year age group used more antibiotics 9 (69.2\%). In terms of the last six months 49 (38\%) of 35-44 year old reported using antibiotics. The 35-44 year age category reported the highest percentage of antibiotic use in the last year. The respondents in the 16-24 year age group were the highest (55\%) in not remembering the last time they used antibiotics. Government employees showed the highest percentage (36.5\%) out of the total 110 respondents who consumed antibiotics in last one month as compared to any other profession.

The relationship of last use of antibiotics with household composition was statistically significant (chi-square $=43.221, p=0.013$ ). The details are shown in Table 2. Significant differences, in terms of antibiotic consumption, were identified among various socioeconomic groups and among varying education levels. In the category of secondary or higher secondary degree, 37 (33.6\%) reported having taken antibiotics within the last month as compared to 19 (17.2\%) of the most educated. Respondents classified as having Bachelor's degree were more likely to have taken antibiotics in the last year with the percentage of $54.0 \%$, this association is statistically significant (chi-square $=27.953, p=$ 0.022 ) as shown in Table 2 . The detailed comparison of antibiotics consumed last time in relation to socioeconomic status is shown in Table 2. The highest percentage of antibiotic use in the last month (42\%) and last 6 months (51.4\%) was in the income category of second wealth quintile $(\geq 20000<$ 30000). The difference between the antibiotic consumption practices and monthly income is statistically significant (chi-sqaure $=36.583, p=$ 0.013).

Table 2: Last Use of Antibiotics in Relation to Social Determinants

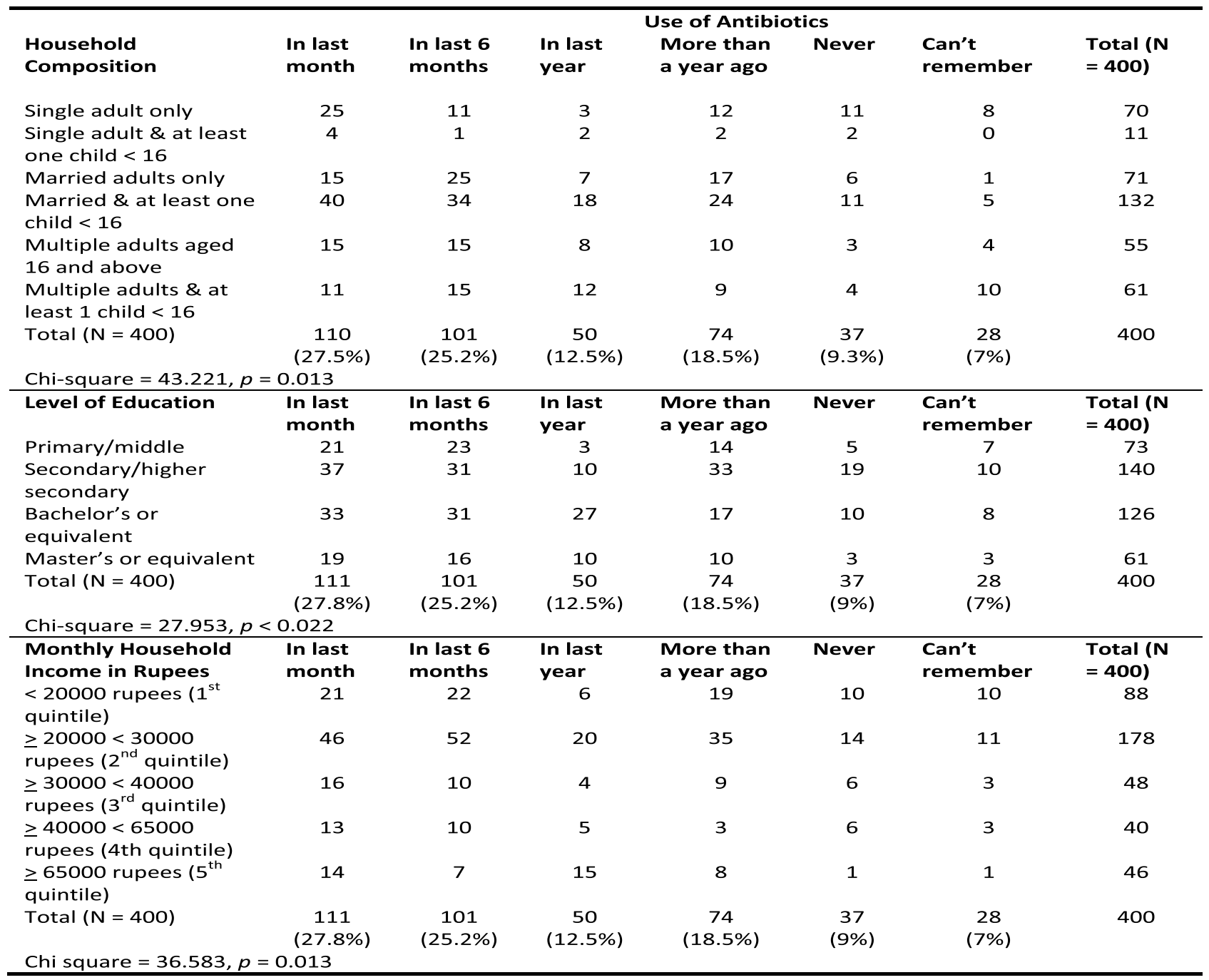


Participants who reported having taken antibiotics $(\mathrm{N}=335)$ were asked whether they had obtained antibiotics from health professionals through prescription or was it non-prescription i.e. (e.g., friends or family, online purchase, previously used/saved antibiotics, etc.). This was followed by asking whether they received advice on how to consume/take them (e.g., with food, for five days). Overall, most respondents $277(82.7 \%)$ reported that they got their antibiotics on a prescription from doctors and 308 (92\%) gave a relatively continuous spread of answers that they did receive advice from a doctor on how to take them, (Figure 2).

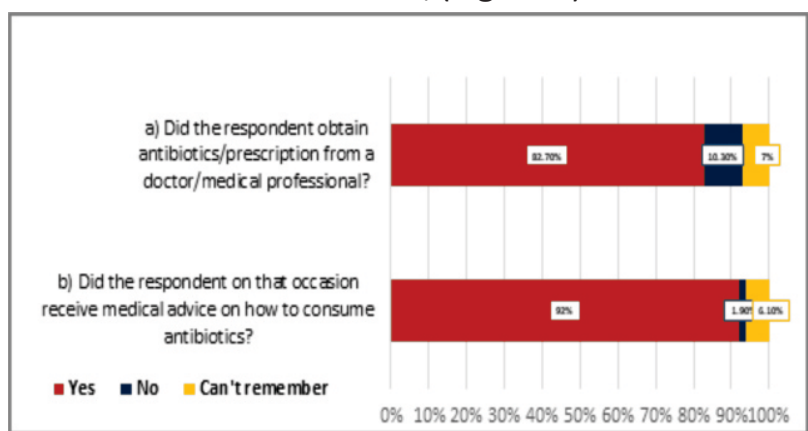

Fig 2: Percentage of Responses from Study Participants $(\mathrm{N}=335)$

a)Obtained Antibiotics through a Medical Professional b)Received Medical Advice on how to take Antibiotics Majority of the respondents (83.7\%) reported having purchased/obtained the antibiotics from a medical store or pharmacy. Only $5.8 \%$ of the respondents received antibiotics from friends or family as shown in Figure 3, and these results were not statistically significant. The only significant finding was the comparison with the level of education. Respondents having basic education and higher secondary education obtained/purchased the antibiotics $(21.4 \% \& 21.4 \%)$ other than a medical store or pharmacy.

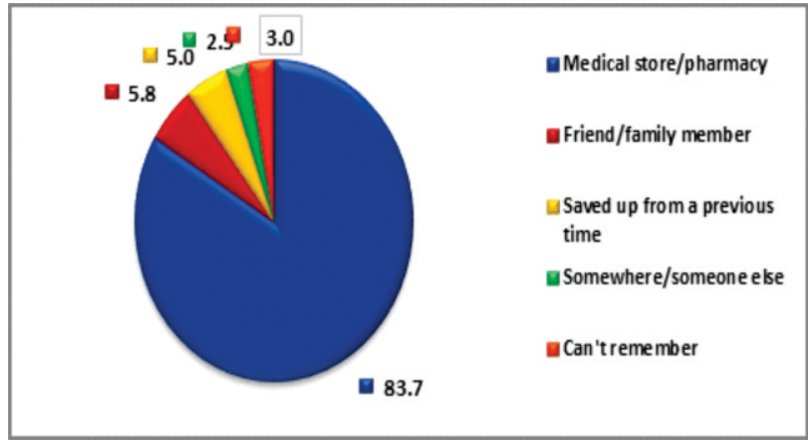

Fig 3: Distribution of Sources from where Antibiotics were Purchased /Acquired by Percentage

\section{Discussion}

High prevalence of antibiotic use is a public health concern for many communities and have been documented in countries like China, India, Greece, Saudi Arabia, and Australia. ${ }^{33-34}$ The results of our study regarding frequency of antibiotic consumption demonstrated that $25.3 \%$ participants consumed antibiotics within the past six months, while $27.5 \%$ used them within the previous month. A survey conducted by WHO in Egypt reported that $76 \%$ of the participants had used antibiotics in the last six months, whereas, a study conducted in Saudi Arabia reported $71 \%$ of the respondents had used an antibiotic in the last six months. ${ }^{23,32}$

In a similar multi-country survey the country in which respondents reported the lowest use in the past six months was Barbados where the number stands at $35 \%$. $^{32}$ The prevalence of antibiotic use is highly relevant to public campaigns on antibiotic resistance as high levels of consumption contribute to the problem of antimicrobial resistance. The participants of the older age groups were more likely to use antibiotics especially in the $45-54$ year old (63.2\%) and $55-64$ year old (69.2\%) year age group. The lower the level of education, higher was the frequency of antibiotic use.

The majority of the people $(82.7 \%)$ reported obtaining antibiotics on a prescription from a doctor, compared to India showed (90\%), Sudan (91\%), though the findings in a survey done in Russian Federation were different where only $56 \%$ of the respondents reported obtaining their antibiotics this way. ${ }^{32}$ El Zowalaty et al. found that $63.6 \%$ of participants purchased antibiotics without a prescription from pharmacies in Saudi Arabia. ${ }^{33}$ In a household survey of 'in-home drug storage and selfmedication' in Iraq, $78 \%$ of participating families admitted self-medication with antibiotics. Worldwide, $50 \%$ of antibiotics used are nonprescribed and are sourced from local medical stores or pharmacies. ${ }^{26}$

Most of our respondents 368 (92\%) reported that they received advice on how to consume antibiotics from a medical professional. Almost $69 \%$ of the respondents from the Russian Federation, 95\% from South Africa, and 95\% from Mexico reported getting advice on how to consume antibiotics. ${ }^{32} \mathrm{~A}$ sizeable majority of people $83.8 \%$ in this study obtained 
antibiotics from a medical store, or pharmacy and results were similar in a survey done by WHO in which $86 \%$ from Nigeria and $83 \%$ from China had obtained antibiotics from a medical stall or store. ${ }^{32}$ No respondent in our study mentioned online purchase of medicines, which is being done in India and China but on a small scale. Our findings indicate that antibiotics are more likely to be taken to treat an appropriate condition or illness and in the prescribed manner, both of which are essential in the context of tackling antibiotic resistance. Incorrectly prescribed antibiotics contribute to the promotion of resistant bacteria. ${ }^{35}$ Another of our notable finding indicates to a practice of obtaining antibiotics other than from a medical store especially in the lower level of education strata.

\section{Conclusion}

Effective education along with close vigilance to the judicious use and antibiotic prescribing should be aimed at both the prescribers and the public as better knowledge is associated with correct behavior of antibiotic/antimicrobial use.

\section{Recommendation}

Suitable and sustainable interventions along with creating awareness in general population should be implemented to fight the global battle against antimicrobial resistance which has become a silent pandemic. Health workers under effective leadership should promote the rational use of antibiotics that must work across Sustainable Development Goals (SDGs) to efficiently manage this unavoidable phenomenon.

\section{REFERENCES}

1. Boyles T, Naicker V, Rawoot N, Raubenheimer P, Eick B, Mendelson $M$. Sustained reduction in antibiotic consumption in a South African public sector hospital: Fouryear outcomes from the Groote Schuur Hospital antibiotic stewardship programme. South African Medical Journal. 2017; 107: 115-8.

2. Horvat $\mathrm{O}$, Mijatović V, Milijasević B, Tomas A, Kusturica MP, Tomić $Z$, et al.There are striking Differences in Outpatient Use of antibiotics Between south Backa District, serbia, and some scandinavian countries? Frontiers in public health. 2018; 6: 91.

3. Klein EY, Van Boeckel TP, Martinez EM, Pant S, Gandra S, Levin SA, et al. Global increase and geographic convergence in antibiotic consumption between 2000 and 2015 . Proceedings of the National Academy of Sciences. 2018; 115: 3463-70.

4. McCullough A, Rathbone J, Parekh S, Hoffmann T, Del Mar C.
Not in my backyard: a systematic review of clinicians' knowledge and beliefs about antibiotic resistance. Journal of antimicrobial chemotherapy. 2015; 70: 2465-73.

5. Núñez-Núñez M, Navarro MD, Gkolia P, Rajendran NB, Del Toro MD, Voss A, et al. Surveillance Systems from Public Health Institutions and Scientific Societies for Antimicrobial Resistance and Healthcare-Associated Infections in Europe (SUSPIRE): protocol for a systematic review. BMJ open. 2017; 7: e014538.

6. Jee Y, Carlson J, Rafai E, Musonda K, Huong TTG, Daza P, et al. Antimicrobial resistance: a threat to global health. The Lancet Infectious Diseases. 2018; 18: 939-40.

7. Robinson TP, Bu DP, Carrique-Mas J, Fevre EM, Gilbert M, Grace D, et al. Antibiotic resistance is the quintessential One Health issue. Trans R Soc Trop Med Hyg. 2016; 110: 377-80.

8. Metcalfe S, Baker MG, Freeman J, Wilson N, Murray P. Combating antimicrobial resistance demands nation-wide action and global governance. NZ Med J. 2016; 129: 8-14.

9. Shallcross LJ, Howard SJ, Fowler T, Davies SC. Tackling the threat of antimicrobial resistance: from policy to sustainable action. Phil Trans R Soc B. 2015; 370: 20140082.

10. Ferri M, Ranucci E, Romagnoli P, Giaccone V. Antimicrobial resistance: A global emerging threat to public health systems. Critical reviews in food science and nutrition. 2017; 57: 2857-76.

11. Holmes AH, Moore LS, Sundsfjord A, Steinbakk M, Regmi S, Karkey $A$, et al. Understanding the mechanisms and drivers of antimicrobial resistance. The Lancet. 2016; 387: 176-87.

12. Jabeen $K$, Bhawan Mal P, Khan E, Chandio S, Jacobsson $S$, Unemo M. Antimicrobial resistance and Neisseria gonorrhoeae multiantigen sequence typing (NG-MAST) genotypes in N. gonorrhoeae during 2012-2014 in Karachi, Pakistan. BMC infectious diseases. 2016; 16: 353.

13. O'Neill J. The Review on Antimicrobial Resistance Antimicrobials in Agriculture and the Environment: Reducing Unnecessary Use and Waste. 2015.

14. Dondorp AM, Limmathurotsakul D, Ashley EA. What's wrong in the control of antimicrobial resistance in critically ill patients from low- and middle-income countries? Intensive Care Med. 2018; 44: 79-82.

15. Inoue $H$, Minghui R. Antimicrobial resistance: translating political commitment into national action. Bulletin of the World Health Organization. 2017; 95: 242.

16. Sarwar MR, Saqib A, Iftikhar S, Sadiq T. Knowledge of community pharmacists about antibiotics, and their perceptions and practices regarding antimicrobial stewardship: a cross-sectional study in Punjab, Pakistan. Infection and Drug Resistance. 2018; 11: 133-45.

17. Mendelson M, Dar OA, Hoffman SJ, Laxminarayan R, Mpundu MM, Røttingen JA. A global antimicrobial conservation fund for low-and middle-income countries. International Journal of Infectious Diseases. 2016; 51: 70-2.

18. Nadimpalli M, Delarocque-Astagneau E, Love DC, Price LB, Huynh BT, Collard JM, et al. Combating Global Antibiotic Resistance: Emerging One Health Concerns in Lower- and Middle-Income Countries. Clinical infectious diseases : an official publication of the Infectious Diseases Society of America. 2018; 66: 963-9.

19. Sharma S, Govender K, Nagaraju K, Chhetri P, Menze T, 
Srinivas SC. Antimicrobial Resistance: Identifying the Major Conflicts of Interest and Way Forward. Indian Journal of Pharmacy Practice. 2017; 10: 69-77.

20. Bhatia R. Universal health coverage framework to combat antimicrobial resistance. Indian Journal of Medical Research. 2018; 147: 228-32.

21. Duffy E, Ritchie S, Metcalfe S, Van Bakel B, Thomas M. Antibacterials dispensed in the community comprise $85 \%-95 \%$ of total human antibacterial consumption. Journal of clinical pharmacy and therapeutics. 2018; 43: 5964.

22. Pouwels KB, Dolk FCK, Smith DR, Robotham JV, Smieszek T. Actual versus 'ideal'antibiotic prescribing for common conditions in English primary care. Journal of Antimicrobial Chemotherapy. 2018; 73: 19-26.

23. Gualano MR, Gili R, Scaioli G, Bert F, Siliquini R. General population's knowledge and attitudes about antibiotics: a systematic review and meta-analysis. Pharmacoepidemiology and Drug Safety. 2015; 24:2-10.

24. Lee $\mathrm{CR}$, Lee JH, Kang LW, Jeong BC, Lee SH. Educational effectiveness, target, and content for prudent antibiotic use. Biomed Res Int. 2015; 2015: 214021.

25. McCullough A, Parekh S, Rathbone J, Del Mar CB, Hoffmann T. A systematic review of the public's knowledge and beliefs about antibiotic resistance. Journal of Antimicrobial Chemotherapy. 2015; 71:27-33.

26. Badger-Emeka LI, Emeka PM, Okosi M. Evaluation of the extent and reasons for increased non-prescription antibiotics use in a University town, Nsukka Nigeria. International Journal of Health Sciences. 2018; 12:11-7.

27. Giannitsioti E, Athanasia S, Plachouras D, Kanellaki S, Bobota F, Tzepetzi G, et al. Impact of patients' professional and educational status on perception of an antibiotic policy campaign: a pilot study at a university hospital. Journal of global antimicrobial resistance. 2016; 6: 123-7.

28. Nicholson A, Tennant I, White L, Thoms-Rodriguez CA, Cook $L$, Johnson S, et al. The knowledge, attitudes and practices of doctors regarding antibiotic resistance at a tertiary care institution in the Caribbean. Antimicrobial resistance and infection control. 2018; 7:23.

29. Atif M, Sarwar MR, Azeem M, Naz M, Amir S, Nazir K. Assessment of core drug use indicators using WHO/INRUD methodology at primary healthcare centers in Bahawalpur, Pakistan. BMC health services research. 2016; 16: 684.

30. Raza UA, Khursheed T, Irfan M, Abbas M, Irfan UM. Prescription patterns of general practitioners in peshawar, pakistan. Pakistan journal of medical sciences. 2014; 30 : 462-5.

31. Lee CR, Lee JH, Kang LW, Jeong BC, Lee SH. Educational effectiveness, target, and content for prudent antibiotic use. BioMed research international. 2015; 2015: 214021.

32. Organization WH. Antibiotic resistance: Multi-country public awareness survey. 2015

33. El Zowalaty ME, Belkina T, Bahashwan SA, El Zowalaty AE, Tebbens JD, Abdel-Salam HA, et al. Knowledge, awareness, and attitudes toward antibiotic use and antimicrobial resistance among Saudi population. International journal of clinical pharmacy. 2016; 38: 1261-8.

34. Xie DS, Xiang LL, Hu Q, Fu XY, Wang HF, Lai RP, et al. Antibiotic use in Chinese hospitals: a multicenter point-prevalence study. Public health. 2015; 129: 576-8.

35. Ventola CL. The Antibiotic Resistance Crisis: Part 2: Management Strategies and New Agents. Pharmacy and Therapeutics. 2015; 40: 344-52. 